\title{
The Circulating MicroRNA-206 Level Predicts the Severity of Pulmonary Hypertension in Patients with Left Heart Diseases
}

\author{
Peng Jina Wenzhu Gua Yayu Laia Wei Zheng ${ }^{a}$ Qi Zhou ${ }^{\mathrm{b}} \quad$ Xiaojing Wu \\ aCardiovascular Department of Xinqiao Hospital, Third Military Medical University, Chongqing, \\ ${ }^{b}$ Cardiovascular Department of the Second Affiliated Hospital of Chongqing Medical University, \\ Chongqing, China
}

\section{Key Words}

Heart failure $\cdot$ Pulmonary hypertension $\bullet$ Left heart diseases $•$ Biomarker, microRNA

\begin{abstract}
Background: MicroRNA-206 (miR-206), a muscle-specific miRNA, regulates the growth of cardiac myocytes and pulmonary artery smooth muscle cells. However, it remains unknown whether miR-206 is involved in pulmonary hypertension $(\mathrm{PH})$ due to left heart diseases $(\mathrm{PH}-$ LHD). This study was designed to investigate the correlation between miR-206 and PH in patients with LHD. Methods: In 82 consecutively enrolled LHD patients, we examined the serum levels of miR-206 and analyzed its correlations with pulmonary artery systolic pressure (PASP) and cardiac function. Another 36 age- and sex-matched subjects served as healthy controls. Results: The patients were divided into the LHD group $(n=47, \mathrm{PASP}<50 \mathrm{mmHg})$ and the PHLHD group ( $n=35, P A S P \geq 50 \mathrm{mmHg}$ ). The level of miR-206 was significantly decreased in the $\mathrm{PH}$-LHD group compared with that of the LHD and healthy control groups. In addition, the miR206 level was correlated with PASP $(r=-0.305, p<0.001)$ but not with systemic blood pressure. Univariate analyses showed that miR-206, brain natriuretic peptide (BNP), left ventricular ejection fraction and left atrial longitudinal diameter (LAD) were significantly related to PASP. Multivariate regression analysis identified miR-206 as an independent predictive factor for PH. MiR-206 alone (cut-off <0.66) demonstrated a sensitivity of $68.60 \%$ and a specificity of $65.80 \%$ in predicting $\mathrm{PH}$. Moreover, the combination of miR-206, BNP and LAD (cut-off 0.21 ) showed a sensitivity of $97.10 \%$ and a specificity of $80.30 \%$ in predicting PH in LHD patients. Conclusion: A decreased circulating miR-206 level was associated with increased PASP in LHD patients. Thus, the level of miR-206, especially combined with BNP and LAD, might be helpful in the detection of PH in LHD patients.

P. Jin and W-Z. Gu contributed equally to this work. 


\section{Introduction}

Left heart diseases (LHD), including heart failure and cardiac valve diseases, represent the most frequent cause of pulmonary hypertension (PH) $[1,2]$. Regardless of the underlying cardiac diseases, the presence of $\mathrm{PH}$ has been regarded as one of the major causes of symptom aggravation [3]. Early recognition of PH is important for the management of LHD patients. $\mathrm{PH}$ is a hemodynamic definition, and invasive right heart catheterization (RHC) has been considered the gold standard for diagnosis. To date, however, conventional echocardiography continues to be used for the detection of $\mathrm{PH}[4,5]$. RHC is not routinely performed on patients with LHD in clinical practice, which impedes the early diagnosis of PH-LHD.

Circulating biomarkers have been proposed as potentially noninvasive, objective and repeatable parameters for the diagnosis, prognosis, and response to therapy. Serum biomarkers associated with endothelial mediators, inflammation, right ventricular dysfunction, and metabolism have been extensively studied [6, 7]. In particular, biomarkers such as brain natriuretic peptide (BNP), uric acid (UA), and bilirubin [8-11] have been correlated with the severity of $\mathrm{PH}$ and have been used for the risk classification of pulmonary artery hypertension (PAH) in the clinic. However, the value of these biomarkers is limited for the detection of PH in LHD patients because of their non-specific nature.

It was recently recognized that non-protein coding microRNA (miRNA) sequences have a critical role in regulating gene expression in cardiovascular diseases $[12,13]$. Accordingly, aberrant miRNA expressions of miR-145, miR-206, miR-204, miR-21, and others have been implicated in the pathogenesis of PH [14-18]. For example, miR-21 was reported to participate in the pathogenesis of chronic hypoxia-induced pulmonary vascular remodeling [15]. Caruso et al. [16] found that the down-regulation of miR-145 protected against the development of PAH in mice exposed to chronic hypoxia. In studies of PH-LHD, miR-206 attracted much attention because it regulates pulmonary artery smooth muscle cells (PASMCs) and cardiomyocytes. MiR-206 belongs to the miR-1 family and is primarily expressed in skeletal muscle. Recently, miR-206 was shown to be expressed in PASMCs and cardiomyocytes [19-23]. Studies by Yue et al. [19] and Jalali et al. [20] showed that reduction in miR-206 levels increased proliferation and reduced apoptosis of PASMCs. Yang et al. [21] found that increased miR-206 expression induced cardiac hypertrophy and inhibited cell death in cultured cardiomyocytes. PH comprises multiple diseases with different pathogenic characteristics. Although the regulation of miR-206 in hypoxia and monocrotaline-induced PAH models has been well-studied $[18,19]$, it remains largely unknown whether miR-206 is involved in PH-LHD. However, PH develops in LHD. Reports showing that miR-206 regulates the cellular features of both cardiomyocytes and PASMCs strongly suggest its role in PHLHD. Because miRNAs may be released into the circulation and can subsequently affect cell function both locally and at a distance, we hypothesized that miR-206 was associated with the incidence of PH-LHD and could be detected in the peripheral blood samples of PH-LHD patients. To test this hypothesis, we studied the expression pattern and clinical relevance of circulating miR-206 with PH in LHD patients.

\section{Materials and Methods}

Ethics

The study was approved by the Ethics Committee of Xinqiao Hospital of Third Military Medical University. All participants involved in this study received oral and written information regarding the objectives of the study and provided written informed consent.

Study design and participants

Inpatients with LHD were consecutively enrolled from January 2014 to July 2015. According to the current guidelines on the classification of PH, eligible LHD subjects included patients with heart failure with reduced ejection fraction (HFrEF), heart failure with preserved ejection fraction (HFpEF), and cardiac 


\section{Cellular Physiology Cell Physiol Biochem 2017;41:2150-2160

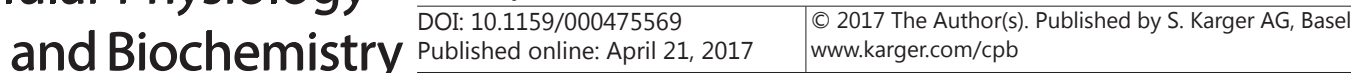 \\ \begin{tabular}{l|l} 
Published onlIne: AprII Z1, $2017 \quad$ www.karger.com/cpb \\
\hline Jin et al: MicroRNA-206 Predicts PH in LHD Patients
\end{tabular}}

valve diseases $[24,25]$. The etiology of heart failure includes coronary artery disease, hypertension and cardiomyopathy, although there is no evidence to indicate that connective tissue disease, congenital heart diseases, diabetes and lung diseases should be included in the etiology of heart failure. Cardiac valve diseases include aortic and mitral valve problems. PH cases of groups 1, 3, 4, and 5 were excluded. The pulmonary artery systolic pressure (PASP) was examined by echocardiography on the day of admission. Finally, 82 cases of LHD were enrolled, and the patients were further divided based on the PASP findings into the LHD control group ( $\mathrm{n}=47, \mathrm{PASP}<50 \mathrm{mmHg}$ ) and the PH-LHD group ( $\mathrm{n}=35, \mathrm{PASP} \geq 50 \mathrm{mmHg}$ ). Another 36 age- and sex-matched subjects served as healthy controls. After informed consent was obtained, peripheral fasting venous blood was drawn from all enrolled subjects for analysis of miR-206 and BNP.

\section{Clinical measurements}

Echocardiographic recordings were obtained in all subjects using a GE VIVID7 color Doppler ultrasound system (GE Healthcare, Norway). The data were stored on a DVD and analyzed by two independent investigators. The simplified Bernoulli equation describes the relationship between tricuspid regurgitation velocity and the peak pressure gradient of tricuspid regurgitation, where the peak pressure gradient of tricuspid regurgitation $=4 \times$ (tricuspid regurgitation velocity). The PASP was calculated as the tricuspid regurgitation pressure gradient plus the estimated right atrial pressure. The right atrial pressure was assumed to be a fixed value of $10 \mathrm{mmHg}$. The left ventricular ejection fraction (LVEF) was calculated using the Teichholz method and the modified biplane Simpson method, as previously described [26]. The blood pressure (BP) and heart rate (HR) were measured with an Omron HEM-6200 monitor (Japan).

The levels of BNP were assayed with a ReLIA Analyzer SSJ-2 using reagents provided by the manufacturer (ReLIA Biotechnologies, USA).

\section{MicroRNA analysis by real-time PCR}

Approximately $3 \mathrm{ml}$ of blood was collected in a vacuum tube at the time of enrollment. Total RNA from the serum samples was extracted using a miRNeasy Mini Kit (Qiagen, Germany) according to the Qiagen supplementary protocol. First-strand cDNA was made using a PrimeScript RT reagent kit (Takara, Japan) from $2 \mu$ total RNA. Quantitative real-time PCR was performed with a StepOnePlus system (Applied Biosystems, America) using SYBR Premix Ex Taq (Takara, Japan). The stem-loop reverse transcription primers and PCR primers for the genes of interest were purchased from Ribobio (Guangzhou, China). The miRNA expression values were normalized to the snRNA U6 expression data and were calculated using the $2^{-\Delta \Delta C t}$ relative quantification method.

\section{Statistical analysis}

Statistical analysis was performed usingSPSS software (version 20.0,IBM corp.,America). Allcontinuous variables are summarized as medians and interquartile ranges, and all categorical variables are expressed as proportions. Significant differences in the biomarker levels between the groups were determined using a Kruskal-Wallis non-parametric test followed by pairwise multiple comparisons. Correlations between the miR-206 level and clinical data, including PASP, BNP and LVEF, were assessed by calculating Spearman's correlation coefficients. Predictive factors were examined by univariate and multivariate analysis. The diagnostic accuracies of serum biomarker levels were assessed by receiver operating characteristic (ROC) curve analysis. All points of each ROC curve were used as independent variables in the formula "Index = Sensitivity + Specificity -1 ". Then, the maximum value of the index (Youden's index) was used as a criterion for selecting the optimum cut-off point, and the corresponding sensitivity and specificity values were the sensitivity and specificity in diagnosing PH-LHD. Forward stepwise binary logistic regression analyses were performed to determine the optimal combination of biomarkers for predicting PH-LHD. P $<0.05$ was considered statistically significant.

\section{Results}

Patient characteristics

The study sample comprised 36 healthy control subjects, 47 LHD control patients, and 35 PH-LHD patients. The average age and sex were comparable among the three groups. 
Table 1. Clinical characteristics of the enrolled subjects. Results are expressed as median (interquartile range) or n (\%). ${ }^{*} \mathrm{P}<0.05,{ }^{* *} \mathrm{P}<0.01$ vs. healthy control group. $\dagger \mathrm{P}<0.05,+\uparrow \mathrm{P}<0.01$ vs. LHD control group. BMI: body mass index, SBP: systolic blood pressure, DBP: diastolic blood pressure, mBP: mean blood pressure, HR: heart rate, NYHA: New York Heart Association, LAD: left atrial longitudinal diameter, LVD: left ventricular end-diastolic diameter, RAD: right atrial diameter, RVD: right ventricular end-diastolic diameter, PAD: pulmonary artery diameter, PASP: pulmonary artery systolic pressure, LVEF: left ventricular ejection fraction, LVFS: left ventricular fractional shortening, BNP: brain natriuretic peptide

\begin{tabular}{|c|c|c|c|c|}
\hline \multirow[b]{2}{*}{ Variables } & \multicolumn{3}{|c|}{ Groups } & \multirow[b]{2}{*}{$P$ value } \\
\hline & $\begin{array}{l}\text { Healthy control } \\
\qquad(n=36)\end{array}$ & LHD control ( $n=47)$ & PH-LHD $(n=35)$ & \\
\hline $\begin{array}{l}\text { Left heart disease } \\
(n, \%)\end{array}$ & & & & - \\
\hline $\begin{array}{l}\text { Coronary artery } \\
\text { disease }\end{array}$ & - & $22(46.81)$ & $12(34.29)$ & - \\
\hline Cardiomyopathy & - & $6(12.77)$ & $8(22.86)$ & - \\
\hline $\begin{array}{l}\text { Cardiac valve } \\
\text { disease }\end{array}$ & - & $9(19.15)$ & $10(28.57)$ & - \\
\hline Hypertension & - & $10(21.28)$ & $5[14.29]$ & - \\
\hline Age (years) & $\begin{array}{c}57.50 \\
(52.00,67.00)\end{array}$ & $64.00(54.00,72.00)$ & $64.00(53.00,73.00)$ & 0.075 \\
\hline Female $(n, \%)$ & $18(50.00)$ & $21(44.68)$ & $18(51.43)$ & 0.810 \\
\hline Smoking $(n, \%)$ & $16(44.44)$ & $19(40.43)$ & $10(28.57)$ & 0.359 \\
\hline BMI $\left(\mathrm{kg} / \mathrm{m}^{2}\right)$ & $\begin{array}{l}23.00(22.01 \\
25.00)\end{array}$ & $22.91(21.26,25.77)$ & $\begin{array}{c}20.76(17.78,22.60) \\
* *,+\dagger\end{array}$ & $<0.001$ \\
\hline SBP (mmHg) & $\begin{array}{c}128.00(120.00, \\
136.75)\end{array}$ & $\begin{array}{c}132.00(117.00 \\
152.00)\end{array}$ & $\begin{array}{c}120.00(108.00 \\
132.00)\end{array}$ & 0.008 \\
\hline DBP (mmHg) & $\begin{array}{c}78.50(72.00 \\
86.50]\end{array}$ & $79.00(70.00,89.00)$ & $71.00(63.00,87.00)$ & 0.222 \\
\hline $\mathrm{mBP}(\mathrm{mmHg})$ & $\begin{array}{l}93.17(90.25 \\
103.00)\end{array}$ & $96.67(88.67,107.67)$ & $89.00(76.67,99.67)$ & 0.054 \\
\hline HR (beats/min) & $\begin{array}{l}72.50[64.50 \\
78.00]\end{array}$ & $70.00(66.00,82.00)$ & $79.00(64.00,86.00)$ & 0.221 \\
\hline NYHA class $[n, \%]$ & & $* *$ & $* *,+\dagger$ & $<0.001$ \\
\hline I & - & $5(10.64)$ & $1(2.86)$ & - \\
\hline II & - & $27(57.45)$ & $7(20.00)$ & - \\
\hline III & - & $14(29.79)$ & $20(57.14)$ & - \\
\hline IV & - & $1(2.13)$ & $7(20.00)$ & - \\
\hline Echocardiography & $32.00(29.00$ & $37.00(33.00,44.00)$ & $47.50(40.00,52.00)$ & \\
\hline $\mathrm{LAD}(\mathrm{mm})$ & $34.00)$ & $* *$ & ${ }^{* *}, \dagger \dagger$ & $<0.001$ \\
\hline $\operatorname{LVD}(\mathrm{mm})$ & $\begin{array}{l}43.50(41.00 \\
46.00)\end{array}$ & $45.70(43.00,48.00)$ & $53.00(46.00,63.00) * *$ & $<0.001$ \\
\hline RAD (mm) & $\begin{array}{l}33.50[32.00 \\
35.50]\end{array}$ & $36.00(33.00,39.00)$ & $\begin{array}{c}45.00(39.60,50.00) \\
* *,+\dagger\end{array}$ & $<0.001$ \\
\hline $\operatorname{RVD}(\mathrm{mm})$ & $\begin{array}{l}33.00(31.00, \\
34.00)\end{array}$ & $35.00(32.00,37.00)$ & $\begin{array}{l}40.00 \quad(36.00,45.00) \\
* *, \dagger\end{array}$ & $<0.001$ \\
\hline $\mathrm{PAD}(\mathrm{mm})$ & $\begin{array}{l}23.00(21.00, \\
23.15]\end{array}$ & $23.00(21.00,25.00)$ & $\begin{array}{c}25.00(24.00,31.00) \\
* *,+\dagger\end{array}$ & $<0.001$ \\
\hline PASP (mmHg) & $\begin{array}{l}26.00(10.00 \\
30.00)\end{array}$ & $33.00(10.00,42.00)$ & $\begin{array}{c}62.00(55.00,72.00) \\
* *,+\dagger\end{array}$ & $<0.001$ \\
\hline LVEF (\%) & $\begin{array}{l}65.00(63.00 \\
70.00)\end{array}$ & $65.00(57.00,70.00)$ & $\begin{array}{c}45.00(37.00,62.00) \\
*,+\dagger\end{array}$ & $<0.001$ \\
\hline LVFS (\%) & $\begin{array}{l}36.00[34.00 \\
39.00]\end{array}$ & $35.50(30.00,39.00)$ & $\begin{array}{c}23.00(18.00,32.40) \\
* * *+\dagger\end{array}$ & $<0.001$ \\
\hline $\begin{array}{l}\text { Biomarkers } \\
\text { miR-206 }\end{array}$ & $1.00(0.54,2.20)$ & $1.04(0.42,2.06)$ & $0.46(0.28,0.91) *, \dagger$ & $<0.001$ \\
\hline BNP $(p g / m l)$ & $\begin{array}{c}43.00(18.30 \\
69.00)\end{array}$ & $75.10(23.10,336.00)$ & $\begin{array}{l}616.00(312.00 \\
1810.00)^{* *},+\dagger\end{array}$ & $<0.001$ \\
\hline Treatments & & $\begin{array}{c}\text { Beta-blockers } \\
(63.83 \%), \text { ACEI/ARB } \\
\text { (72.34\%), aldosterone } \\
\text { antagonist }(40.43 \%) \text {, } \\
\text { diuretics }(44.68 \%) \text {, } \\
\text { statins }(68.09 \%) \text {, } \\
\text { digitalis }(0.00 \%) \text {, } \\
\text { beraprost }(4.26 \%) \text {, } \\
\text { anticoagulant and/or } \\
\text { antiplatelet therapy } \\
(80.85 \%)\end{array}$ & $\begin{array}{c}\text { Beta-blockers } \\
\text { (74.29\%), ACEI/ARB } \\
\text { (77.14\%), aldosterone } \\
\text { antagonist }(85.71 \%) \text {, } \\
\text { diuretics }(91.43 \%) \text {, } \\
\text { statins }(42.86 \%), \\
\text { digitalis }(54.29 \%) \text {, } \\
\text { beraprost }(37.14 \%) \text {, } \\
\text { anticoagulant and/or } \\
\text { antiplatelet therapy } \\
(77.14 \%)\end{array}$ & \\
\hline
\end{tabular}

Fig. 1. Levels of miR-206 in the healthy control, LHD control, and PH-LHD groups. In the 35 consecutively enrolled PH-LHD patients, 47 LHD control patients and 36 healthy control subjects, the plasma levels of miR-206 were analyzed by real-time PCR. The miR-206 expression values were normalized to the internal snRNA U6 expression and were calculated with the $2^{-\Delta \Delta C t}$ relative quantification method. The expression of miR-206 was significantly lower in the PH-LHD group than that in the LHD and healthy control groups. LHD=left heart diseases, PH-LHD=pulmonary hypertension due to left heart diseases. $* * \mathrm{p}<0.01$.

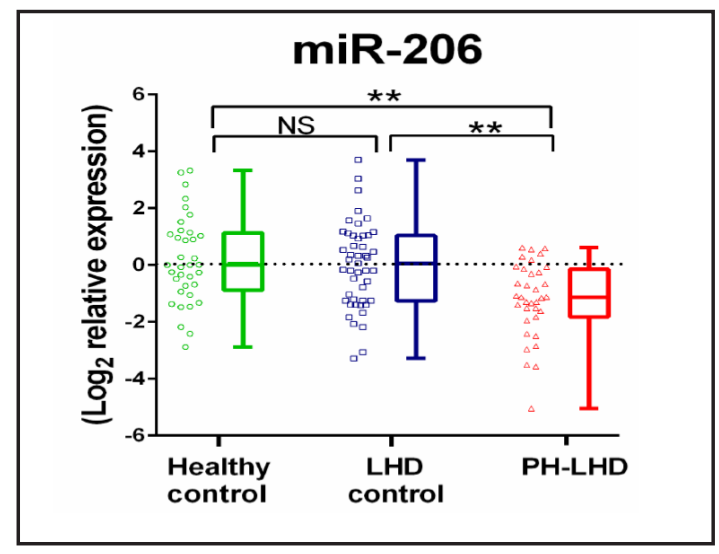

The median PASP was $26.00 \mathrm{mmHg}$ (interquartile range, [IQR], 10.00 to $30.00 \mathrm{mmHg}$ ) in the healthy controls, $33.00 \mathrm{mmHg}$ (IQR, 10.00 to $42.00 \mathrm{mmHg}$ ) in the LHD control group, and $62.00 \mathrm{mmHg}$ (IQR, 55.00 to $72.00 \mathrm{mmHg}$ ) in the PH-LHD group. The pulmonary artery diameter (PAD) was $23.00 \mathrm{~mm}$ (IQR, 21.00 to $23.15 \mathrm{~mm}$ ) in the healthy controls, $23.00 \mathrm{~mm}$ (IQR, 21.00 to $25.00 \mathrm{~mm}$ ) in the LHD control group, and $25.00 \mathrm{~mm}$ (IQR, 24.00 to 31.00 $\mathrm{mm}$ ) in the PH-LHD group. The PASP and PAD were significantly increased in the PH-LHD 
Table 2. Correlations of miR-206 level with clinical data. PASP: pulmonary artery systolic pressure, SBP: systolic blood pressure, A DBP: diastolic blood pressure, CO: cardiac output, LAD: left atrial longitudinal diameter, LVD: left ventricular end-diastolic diameter, RAD: right atrial diameter, RVD: right ventricular end-diastolic diameter, PAD: pulmonary artery diameter, LVEF: left ventricular ejection fraction, NYHA: New York Heart Association, BNP: brain natriuretic peptide

\begin{tabular}{lcc}
\hline Variables & $r$ value & $P$ value \\
\hline Age & -0.164 & 0.075 \\
Female sex & -0.007 & 0.926 \\
Heart rate & -0.059 & 0.528 \\
Hemodynamics & & \\
$\quad$ PASP & -0.305 & $<0.001$ \\
$\quad$ SBP & 0.065 & 0.486 \\
$\quad$ DBP & 0.023 & 0.803 \\
Echocardiography & & \\
$\quad$ LAD & -0.181 & 0.049 \\
$\quad$ LVD & -0.259 & 0.005 \\
$\quad$ RAD & -0.161 & 0.082 \\
$\quad$ RVD & -0.133 & 0.151 \\
$\quad$ PAD & -0.079 & 0.395 \\
LVEF & 0.226 & 0.014 \\
NYHA class & -0.194 & 0.035 \\
BNP & -0.178 & 0.062 \\
\hline
\end{tabular}

Fig. 2. Correlations of miR-206 and hemodynamic parameters, In the 35 PH-LHD patients, 47 LHD control patients and 36 healthy control subjects the correlations of miR-206 level with PASP and systemic blood pressure were assessed by calculating Spearman's correlation coefficients. Decreased levels of miR-206 were correlated with increased PASP but not systemic blood pressure. A: correlation of miR-206 level with PASP; B: correlation of miR-206 level with SBP; C: correlation of miR-206 level with DBP. $\mathrm{PASP}=$ pulmonary artery systolic pressure, $\mathrm{SBP}=$ systolic blood pressure; DBP=diastolic blood pressure; LHD=left heart diseases, PH-LHD=pulmonary hypertension due to left heart diseases.

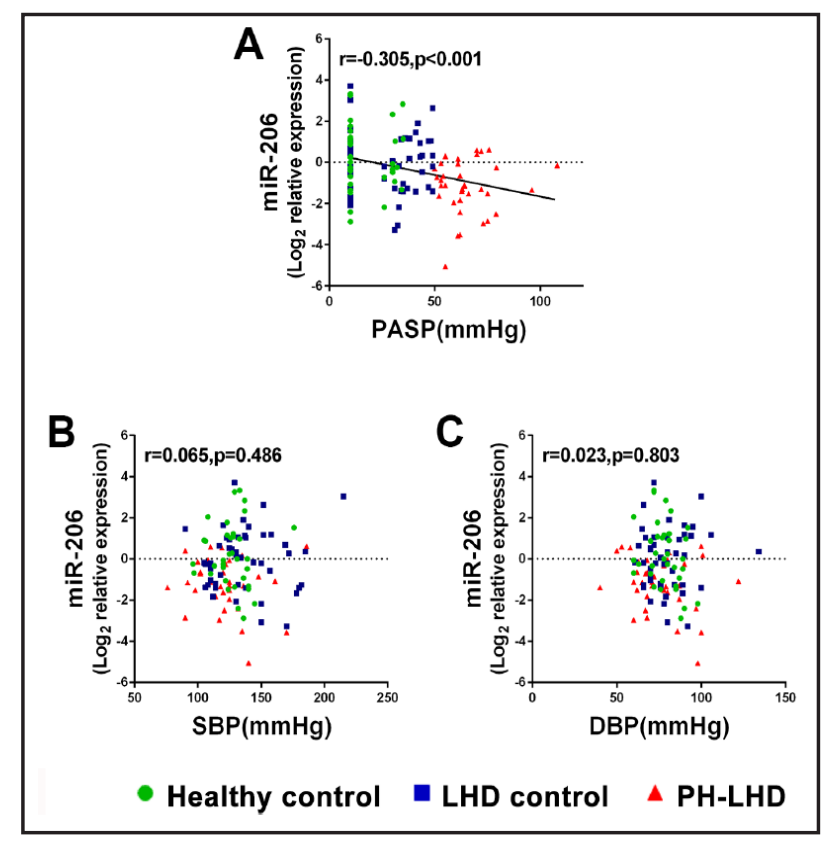

group compared with the LHD and healthy control groups. The atrium and ventricle were significantly enlarged in the PH-LHD group compared with the LHD group. The chamber sizes of the atrium and ventricle, with the exception of the left atrial longitudinal diameter (LAD), were comparable between the healthy control and LHD groups. The LAD was enlarged in the LHD group compared with the healthy control group. Cardiac function was significantly decreased in the PH-LHD group compared with the LHD control and healthy control groups. The percentage of New York Heart Association (NYHA) grades III and IV was increased and the LVEF was decreased in the PH-LHD group compared with the LHD group. The BNP level was consistently and significantly increased in the PH-LHD group compared with the LHD and healthy control groups (Table 1).

\section{Expression of miR-206}

Overall, the plasma levels of miR-206 were similar between the male and female subjects. There was no correlation between the miR-206 level and age. However, miR-206 expression was significantly lower in the PH-LHD group than that in the LHD and healthy control groups $(\mathrm{p}<0.01)$. No significant difference was found between the healthy control and LHD control groups (Fig. 1, Table 1). 
Table 3. Univariate and multivariate logistic regression analysis of variables associated with pulmonary hypertension due to left heart disease. BMI: body mass index, SBP: systolic blood pressure, DBP: diastolic blood pressure, HR: heart rate, LAD: left atrial longitudinal diameter, LVD: left ventricular end-diastolic diameter, RAD: right

\begin{tabular}{lcccc}
\hline \multirow{2}{*}{ Variables } & \multicolumn{2}{c}{ Univariate analysis } & \multicolumn{2}{c}{ Multivariate analysis } \\
& OR $(95 \% \mathrm{CI})$ & $P$ value & OR $(95 \% \mathrm{CI})$ & $P$ value \\
\hline Age (years) & $1.020(0.985-1.055)$ & 0.270 & - & - \\
Female sex & $1.195(0.542-2.634)$ & 0.659 & - & - \\
Smoking & $0.549(0.234-1.287)$ & 0.168 & - & - \\
BMI $\left(\mathrm{kg} / \mathrm{m}^{2}\right)$ & $0.763(0.655-0.888)$ & $<0.001$ & - & - \\
HR (beats/min) & $1.035(1.001-1.071)$ & 0.045 & - & $<0.001$ \\
LAD (mm) & $1.214(1.128-1.307)$ & $<0.001$ & $1.166(1.077-1.262)$ & - \\
LVD (mm) & $1.119(1.061-1.180)$ & $<0.001$ & - & - \\
RAD (mm) & $1.179(1.102-1.263)$ & $<0.001$ & - & - \\
RVD (mm) & $1.166(1.081-1.259)$ & 0.001 & - & - \\
LVEF (\%) & $0.926(0.895-0.958)$ & $<0.001$ & - & - \\
LVFS (\%) & $0.861(0.812-0.914)$ & $<0.001$ & - & 0.009 \\
NYHA class III/IV & $6.359(3.179-12.718)$ & $<0.001$ & - & -0.010 \\
miR-206 & $0.269(0.120-0.601)$ & 0.001 & $0.198(0.059-0.671)$ & \\
BNP $/ 1000(\mathrm{pg} / \mathrm{ml})$ & $6.463(2.653-15.745)$ & $<0.001$ & $4.191(1.402-12.530)$ & 0.010 \\
\hline
\end{tabular}
atrial diameter, RVD: right $\mathrm{BNP} / 1000(\mathrm{pg} / \mathrm{ml}) \quad 6.463(2.653-15.745)$ ventricular end-diastolic diameter, mBP: mean blood pressure, PAD: pulmonary artery diameter, LVEF: left ventricular ejection fraction, LVFS: left ventricular fractional shortening, NYHA: New York Heart Association, BNP: brain natriuretic peptide

Table 4. Data from ROC curves. \# Predicted probability generated using multivariate logistic regression analysis, AUC: area under ROC curve, SE: standard error, CI: confidence interval, LAD: left atrial longitudinal diameter, BNP: brain natriuretic peptide

\begin{tabular}{lcccccccc}
\hline Biomarkers & AUC & SE & $95 \%$ CI & Pvalue & Cut-off & Sensitivity & Specificity & $\begin{array}{c}\text { Youden } \\
\text { index }\end{array}$ \\
\hline miR-206 & 0.720 & 0.049 & $0.624 \sim 0.815$ & $<0.001$ & 0.66 & 0.686 & 0.658 & 0.344 \\
LAD (mm) & 0.871 & 0.032 & $0.807 \sim 0.934$ & $<0.001$ & 35.50 & 1.000 & 0.618 & 0.618 \\
BNP (pg/ml) & 0.879 & 0.032 & $0.815 \sim 0.942$ & $<0.001$ & 88.25 & 0.943 & 0.724 & 0.667 \\
miR-206, LAD & 0.930 & 0.023 & $0.885 \sim 0.976$ & $<0.001$ & 0.21 & 0.971 & 0.803 & 0.774 \\
\& BNP (\#) & & & & & & & & \\
\hline
\end{tabular}

Fig. 3. ROC curve analysis, The diagnostic accuracies of miR-206, LAD and BNP were determined by the ROC analysis. Forward stepwise binary logistic regression analysis showed that the combination of miR-206, BNP and LAD demonstrated a better predictive value than that of each individual biomarker. $\mathrm{LAD}=$ left atrial longitudinal diameter; $\mathrm{BNP}=$ brain natriuretic peptide; $\mathrm{ROC}=$ receiver operating characteristic.

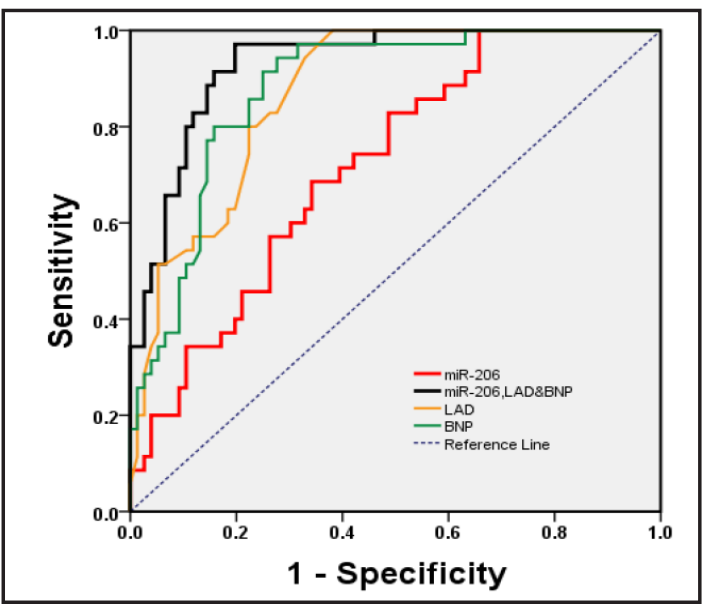

Correlations between the circulating miR-206 level and clinical measurements

Because the clinical parameters, including pulmonary hemodynamic data, chamber size of the atrium and ventricle, LVEF and BNP, were significantly different between the PH-LHD and LHD groups, we further analyzed their correlations with the miR-206 level. Spearman's correlation analysis showed that the miR-206 level was negatively correlated with PASP $(\mathrm{r}=-$ 0.305, $\mathrm{p}<0.001$ ) but not SBP ( $\mathrm{r}=0.065, \mathrm{p}=0.486$ ) or DBP ( $\mathrm{r}=0.023, \mathrm{p}=0.803$ ) (Fig. 2). The miR206 level was negatively correlated with $\operatorname{LVD}(\mathrm{r}=-0.259, \mathrm{p}<0.05)$ and $\mathrm{BNP}(\mathrm{r}=-0.178, \mathrm{p}<0.05)$ and positively correlated with LVEF $(r=0.226$, $p<0.05)$ (Table 2).

The predictive potential for $\mathrm{PH}$ by miR-206

Univariate and multivariate analyses were further performed to identify the factors related to the prediction of $\mathrm{PH}$. We used the univariate analysis to select the predictive factors of PH, and the results showed that miR-206 ( $p=0.001)$, BNP $(p<0.001)$, LVEF $(p<0.001)$, 


\section{Cellular Physiology Cell Physiol Biochem 2017;41:2150-2160 \\ \begin{tabular}{c|c|c|} 
DOI: 10.1159/000475569 & O 2017 The Author(s). Published by S. Karger AG, Basel \\
www.karger.com/cpb
\end{tabular} \\ Jin et al.: MicroRNA-206 Predicts PH in LHD Patients}

NYHA class $(p<0.001)$, LAD $(p<0.001), \operatorname{LVD}(p<0.001)$, RAD $(p<0.001)$ and RVD $(p=0.001)$ were significantly related to $\mathrm{PH}$. Predictive factors selected from the univariate analysis were used as variables for the forward stepwise multivariate logistic regression. MiR-206, LAD and BNP were further entered into the multivariate logistic regression analysis. MiR-206 (OR 0.198, 95\% CI 0.059-0.671, $\mathrm{p}<0.01$ ) was identified as an independent predictive factor for PH in LHD patients (Table 3).

The diagnostic accuracies of miR-206, LAD and BNP determined by the ROC analysis are shown in Table 4. MiR-206 alone (cut off 0.66 ) demonstrated a sensitivity of $68.60 \%$ and specificity of $65.80 \%$ with area under the curve (AUC) of 0.720 in predicting $\mathrm{PH}$. Forward stepwise binary logistic regression analysis showed that the combination of miR-206, BNP and LAD had a better predictive value, with an AUC of 0.930 and Youden index of 0.774 , than that of each individual biomarker alone. The logistic formula

$$
\mathrm{P}=\frac{1}{1+\exp (-Z)}
$$

was used to calculate the probability of miR-206, BNP and LAD in predicting PH. $\mathrm{Z}=\beta_{0}+\beta_{1} \mathrm{X}_{1}+\beta_{2} \mathrm{X}_{2}+\ldots \ldots+\beta_{\mathrm{m}} \mathrm{X}_{\mathrm{m}} \cdot \beta_{0}$ is a constant, and $\beta_{1}, \beta_{2}, \ldots \ldots . \beta_{\mathrm{m}}$ are estimated regression coefficients of the risk factors. Thus, the predicted probability was calculated as follows:

$$
\text { Predicted probability }=\frac{1}{1+\exp [6.452+1.618 X(\operatorname{miR} 206)-0.153 X(L A D)-1.433 X(B N P / 1000)]}
$$

The combination of miR-206, LAD and BNP (cut-off 0.21 ) showed a sensitivity of $97.10 \%$ and a specificity of $80.30 \%$ in the prediction of PH in LHD patients (Fig. 3, Table 4).

\section{Discussion}

The importance of circulating biomarkers, based on their objective, repeatable and noninvasive nature, has aroused great interest for predicting the severity of PH in LHD patients. Our study showed that miR-206 levels were significantly reduced in PH-LHD patients, and this decrease was negatively correlated with an increase in PASP but not systemic blood pressure. In the univariate logistic regression analysis, miR-206 as well as BNP, LVEF, NYHA class and the chamber size of the atrium and ventricle were significantly related to the severity of $\mathrm{PH}$ in LHD patients. Our multivariate logistic regression analysis further showed that miR-206 was an independent predictor for PH in LHD patients.

$\mathrm{PH}$ is a common complication of LHD patients, with an incidence ranging between $65 \%$ and $80 \%[1,27,28]$. PH-LHD belongs to group $2 \mathrm{PH}$ according to the current guidelines on PH classification. In contrast to idiopathic pulmonary artery hypertension (IPAH), PH-LHD typically develops in LHD in response to a passive backward transmission of filling pressures [3]. The mechanism regulating cardiac hypertrophy and heart failure might simultaneously affect pulmonary vascular remodeling. Among the specific mechanisms controlling $\mathrm{PH}$ and cardiac hypertrophy, non-protein-coding miRNA sequences have attracted attentions for their integrative functions in cardiovascular diseases [29]. MiR-206 belongs to the miR-1/ miR-206 family of miRNAs and has been identified as an important modulator of muscle growth. MiR-206 is expressed in cardiomyocytes, and a study by Yang et al. [21] showed that miR-206 induces cardiac hypertrophy and protects myocytes against cell death. MiR-206 is also expressed in PASMCs and affects the proliferation of PASMCs by targeting Notch3 or the HIF- $1 \alpha$ signaling pathway $[19,20]$. To date, however, no study has determined whether miR206 is involved in PH-LHD.

MiRNAs can be released into the circulation and might subsequently affect cell function both locally and at a distance. In this study, we enrolled 82 cases with LHD and 36 healthy control subjects and analyzed their plasma miR-206 levels. Because decreased Dicer/Drosha expression was associated with $\mathrm{PH}$, and an overall reduction in miRNA processing may be observed [14], the levels of miR-206 were normalized to the internal snRNA U6 expression in this study. We found that the miR-206 level was comparable between the male and female 


\section{Cellular Physiology Cell Physiol Biochem 2017;41:2150-2160

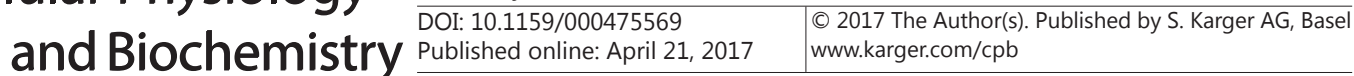 \\ Jin et al.: MicroRNA-206 Predicts PH in LHD Patients}

subjects. Additionally, there was no correlation between miR-206 level and age. However, the circulating level of miR-206 was significantly different between the LHD patients with and without PH. In particular, the miR-206 level was significantly decreased in PH-LHD patients compared with that in LHD patients, suggesting that miR-206 might be involved in the progression of $\mathrm{PH}$ in LHD patients.

In clinical practice, the impairment of left ventricle remodeling and function has been regarded as a primary risk factors of PH in LHD patients [30]. Consistent with previous reports, our study showed that the atrium and ventricle were significantly enlarged in the PH-LHD group compared with the LHD group. Furthermore, cardiac function, assessed by NYHA class and LVEF, was also significantly decreased, while the BNP level was increased, in the PH-LHD group compared with the LHD group. The miR-206 level was also correlated with changes in LVD, LVEF and BNP. Moreover, decreased levels of miR-206 were negatively correlated with increases in PASP but not systemic blood pressure. These findings indicated that the decreased expression of miR-206 reflects the severity of LHD and impaired pulmonary hemodynamics.

In addition to traditional risk factors, including LVEF, NYHA class and cardiac remodeling, the miR-206 level was significantly associated with the risk of PH. Further multivariate logistic regression analyses showed that miR-206, LAD and BNP were independent predictive factors for PH in LHD patients. In our study, LAD, but not LVD, was entered into the multivariate logistic regression analysis, which might be due to the relatively thin wall thickness and better compliance of the LA compared with the LV or because the LA is more sensitive to changes in pulmonary hemodynamics [31]. Further ROC analyses indicated that miR-206 alone (cut-off $<0.66$ ) demonstrated a sensitivity of $68.60 \%$ and a specificity of $65.80 \%$ in the prediction of $\mathrm{PH}$. Forward stepwise binary logistic regression analyses showed that the combination of miR-206, BNP and LAD demonstrated a better predictive value than each of these biomarkers alone. This combination panel (cut-off 0.210 ) showed a sensitivity of $97.10 \%$ and a specificity of $80.30 \%$ in the prediction of PH in LHD patients. The progression of LHD into PH-LHD involves complex mechanisms including hemodynamic changes, cardiac remodeling and neuroendocrine factors [3]. The potential for biomarker combinations is currently of considerable interest in the prediction of PH in LHD patients, and our study suggests that a combination of miRNA expression, cardiac remodeling and neuroendocrine biomarkers might be helpful for the screening and identification of PH in LHD patients.

\section{Limitations}

There are several limitations to this study. First, as a single center study with a small sample size, the predictive value should be interpreted with caution. An expanded random sample across all genders and ages should be more representative of the general population, and larger clinical studies are required to determine the predictive potential of miR-206 on the severity of $\mathrm{PH}$ in patients with LHD. The second limitation was the inaccuracy of the noninvasive methods in assessing pulmonary artery pressure. However, more accurate, invasive RHC measurements could not be obtained in healthy and LHD controls due to ethical considerations. Noninvasive echocardiography is widely used in clinical practice, and according to the guidelines for PH diagnosis, the diagnostic accuracy of PH by echocardiography is close to that obtained by RHC when the PASP exceeds $50 \mathrm{mmHg}$ [32]. We therefore used $50 \mathrm{mmHg}$ of PASP as the criterion for PH in this study. Finally, in this study, the BMI was comparable between the healthy control and the LHD group. However, BMI was decreased in the PH-LHD group compared to those in the LHD and healthy control groups. This difference might cause bias in the results. Further analysis of the relationship between miR-206 and BMI should be undertaken. 


\section{Cellular Physiology Cell Physiol Biochem 2017;41:2150-2160 \begin{tabular}{ll|l} 
and Biochemistry & $\begin{array}{l}\text { DOI: 10.1159/000475569 } \\
\text { Published onlıne: April 21, } 2017\end{array}$ & $\begin{array}{l}\text { (c) } 2017 \text { The Author(s). Published by S. Karger AG, Basel } \\
\text { www.karger.com/cpb }\end{array}$ \\
\hline
\end{tabular} \\ Jin et al.: MicroRNA-206 Predicts PH in LHD Patients}

\section{Conclusion}

$\mathrm{PH}$ is a common complication of LHD. Our study showed that a decreased circulating miR-206 level was associated with increased PASP in LHD patients. In multivariate logistic regression analysis, miR-206 was identified as an independent predictor for PH. Furthermore, miR-206, especially combined with BNP and LAD, demonstrated a better predictive value for PH-LHD. Our study suggests that a combination of miRNA expression, cardiac remodeling and neuroendocrine biomarkers might be helpful for the screening and identification of $\mathrm{PH}$ in LHD patients.

\section{Funding Source}

Projects from the National Scientific Foundation of China (NSFC, grant number 81270109 and 91539104 to X.J.W.).

\section{Acknowledgments}

The authors thank Mrs. Mengyang Deng and Huali Kang for their technical support. We would like to thank all the participants for their support.

\section{Disclosure Statement}

The authors have no disclosures to report.

\section{References}

1 Rosenkranz S, Gibbs JS, Wachter R, De Marco T, Vonk-Noordegraaf A, Vachiery JL: Left ventricular heart failure and pulmonary hypertension. Eur Heart J 2016;37:942-954.

-2 Gerges M, Gerges C, Pistritto AM, Lang MB, Trip P, Jakowitsch J, Binder T, Lang IM: Pulmonary Hypertension in Heart Failure. Epidemiology, Right Ventricular Function, and Survival. Am J Respir Crit Care Med 2015;192:1234-1246.

-3 Breitling S, Ravindran K, Goldenberg NM, Kuebler WM: The pathophysiology of pulmonary hypertension in left heart disease. Am J Physiol Lung Cell Mol Physiol 2015;309:L924-941.

4 Feitell S, Jacob M: New Diagnostic and Therapeutic Strategies for Pulmonary Hypertension Associated with Left Heart Disease. Curr Treat Options Cardiovasc Med 2016;18:18.

-5 Pristera N, Musarra R, Schilz R, Hoit BD: The Role of Echocardiography in the Evaluation of Pulmonary Arterial Hypertension. Echocardiography 2016;33:105-116.

-6 Pezzuto B, Badagliacca R, Poscia R, Ghio S, D'Alto M, Vitulo P, Mule M, Albera C, Volterrani M, Fedele F, Vizza CD: Circulating biomarkers in pulmonary arterial hypertension: update and future direction. J Heart Lung Transplant 2015;34:282-305.

7 Cracowski JL, Leuchte HH: The potential of biomarkers in pulmonary arterial hypertension. Am J Cardiol 2012;110:32s-38s.

8 Casserly B, Klinger JR: Brain natriuretic peptide in pulmonary arterial hypertension: biomarker and potential therapeutic agent. Drug Des Devel Ther 2009;3:269-287.

-9 Takeda Y, Takeda Y, Tomimoto S, Tani T, Narita H, Kimura G: Bilirubin as a prognostic marker in patients with pulmonary arterial hypertension. BMC Pulm Med 2010;10:22. 


\section{Cellular Physiology Cell Physiol Biochem 2017;41:2150-2160

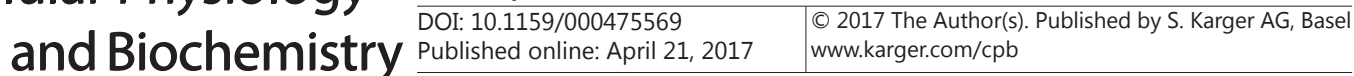 \\ Published online: Aprit21, 2017 www.kargercom/cp}

10 Khosla UM, Zharikov S, Finch JL, Nakagawa T, Roncal C, Mu W, Krotova K, Block ER, Prabhakar S, Johnson RJ: Hyperuricemia induces endothelial dysfunction. Kidney Int 2005;67:1739-1742.

11 Zharikov S, Krotova K, Hu H, Baylis C, Johnson RJ, Block ER, Patel J: Uric acid decreases NO production and increases arginase activity in cultured pulmonary artery endothelial cells. Am J Physiol Cell Physiol 2008;295:C1183-1190.

12 Wang Z, Kang B, Li W, Xi W, Yi Y, Ciren Y, Shen H, Zhang Y, Jiang H, Xiao J: Hydrogen Sulfide Protects Cardiomyocytes against Apoptosis in Ischemia/Reperfusion through MiR-1-Regulated Histone Deacetylase 4 Pathway. Cell Physiol Biochem 2016;41:10-21.

13 Liu H, Chen M, Wu F, Li F, Yin T, Cheng H, Li W, Liu B, Wang Q, Tao L: rs2910164 Polymorphism Confers a Decreased Risk for Pulmonary Hypertension by Compromising the Processing of microRNA-146a. Cell Physiol Biochem 2015;36:1951-1960.

14 Caruso P, MacLean MR, Khanin R, McClure J, Soon E, Southgate M, MacDonald RA, Greig JA, Robertson KE, Masson R, Denby L, Dempsie Y, Long L, Morrell NW, Baker AH: Dynamic changes in lung microRNA profiles during the development of pulmonary hypertension due to chronic hypoxia and monocrotaline. Arterioscler Thromb Vasc Biol 2010;30:716-723.

15 Bienertova-Vasku J, Novak J, Vasku A: MicroRNAs in pulmonary arterial hypertension: pathogenesis, diagnosis and treatment. J Am Soc Hypertens 2015;9:221-234.

16 Caruso P, Dempsie Y, Stevens HC, McDonald RA, Long L, Lu R, White K, Mair KM, McClure JD, Southwood M, Upton P, Xin M, van Rooij E, Olson EN, Morrell NW, MacLean MR, Baker AH: A role for miR-145 in pulmonary arterial hypertension: evidence from mouse models and patient samples. Circ Res 2012;111:290-300.

17 Courboulin A, Paulin R, Giguere NJ, Saksouk N, Perreault T, Meloche J, Paquet ER, Biardel S, Provencher S, Cote J, Simard MJ, Bonnet S: Role for miR-204 in human pulmonary arterial hypertension. J Exp Med 2011;208:535-548.

18 Sharma S, Umar S, Centala A, Eghbali M: Role of miR206 in genistein-induced rescue of pulmonary hypertension in monocrotaline model. J Appl Physiol (1985) 2015;119:1374-1382.

19 Yue J, Guan J, Wang X, Zhang L, Yang Z, Ao Q, Deng Y, Zhu P, Wang G: MicroRNA-206 is involved in hypoxiainduced pulmonary hypertension through targeting of the HIF-1alpha/Fhl-1 pathway. Lab Invest 2013;93:748-759.

20 Jalali S, Ramanathan GK, Parthasarathy PT, Aljubran S, Galam L, Yunus A, Garcia S, Cox RR, Jr., Lockey RF, Kolliputi N: Mir-206 regulates pulmonary artery smooth muscle cell proliferation and differentiation. PLoS One 2012;7:e46808.

21 Yang Y, Del Re DP, Nakano N, Sciarretta S, Zhai P, Park J, Sayed D, Shirakabe A, Matsushima S, Park Y, Tian B, Abdellatif M, Sadoshima J: miR-206 Mediates YAP-Induced Cardiac Hypertrophy and Survival. Circ Res 2015;117:891-904.

-22 Shan ZX, Lin QX, Deng CY, Zhu JN, Mai LP, Liu JL, Fu YH, Liu XY, Li YX, Zhang YY, Lin SG, Yu XY: miR-1/miR206 regulate Hsp60 expression contributing to glucose-mediated apoptosis in cardiomyocytes. FEBS Lett 2010;584:3592-3600.

-23 Limana F, Esposito G, D'Arcangelo D, Di Carlo A, Romani S, Melillo G, Mangoni A, Bertolami C, Pompilio G, Germani A, Capogrossi MC: HMGB1 attenuates cardiac remodelling in the failing heart via enhanced cardiac regeneration and miR-206-mediated inhibition of TIMP-3. PLoS One 2011;6:e19845.

-24 McLaughlin VV, Archer SL, Badesch DB, Barst RJ, Farber HW, Lindner JR, Mathier MA, McGoon MD, Park MH, Rosenson RS, Rubin LJ, Tapson VF, Varga J: ACCF/AHA 2009 expert consensus document on pulmonary hypertension a report of the American College of Cardiology Foundation Task Force on Expert Consensus Documents and the American Heart Association developed in collaboration with the American College of Chest Physicians; American Thoracic Society, Inc.; and the Pulmonary Hypertension Association. J Am Coll Cardiol 2009;53:1573-1619. 


\section{Cellular Physiology Cell Physiol Biochem 2017;41:2150-2160

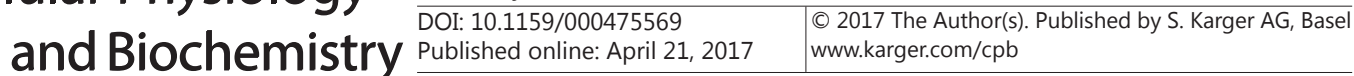 \\ Jin et al.: MicroRNA-206 Predicts PH in LHD Patients}

25 Galie N, Humbert M, Vachiery JL, Gibbs S, Lang I, Torbicki A, Simonneau G, Peacock A, Vonk Noordegraaf A, Beghetti M, Ghofrani A, Gomez Sanchez MA, Hansmann G, Klepetko W, Lancellotti P, Matucci M, McDonagh T, Pierard LA, Trindade PT, Zompatori M, Hoeper M, Aboyans V, Vaz Carneiro A, Achenbach S, Agewall S, Allanore Y, Asteggiano R, Paolo Badano L, Albert Barbera J, Bouvaist H, Bueno H, Byrne RA, Carerj S, Castro G, Erol C, Falk V, Funck-Brentano C, Gorenflo M, Granton J, Iung B, Kiely DG, Kirchhof P, Kjellstrom B, Landmesser U, Lekakis J, Lionis C, Lip GY, Orfanos SE, Park MH, Piepoli MF, Ponikowski P, Revel MP, Rigau D, Rosenkranz S, Voller H, Luis Zamorano J: 2015 ESC/ERS Guidelines for the diagnosis and treatment of pulmonary hypertension: The Joint Task Force for the Diagnosis and Treatment of Pulmonary Hypertension of the European Society of Cardiology (ESC) and the European Respiratory Society (ERS): Endorsed by: Association for European Paediatric and Congenital Cardiology (AEPC), International Society for Heart and Lung Transplantation (ISHLT). Eur Heart J 2016;37:67-119.

26 Allemann Y, Stuber T, de Marchi SF, Rexhaj E, Sartori C, Scherrer U, Rimoldi SF: Pulmonary artery pressure and cardiac function in children and adolescents after rapid ascent to 3,450 m. Am J Physiol Heart Circ Physiol 2012;302:H2646-2653.

27 Lam CS, Roger VL, Rodeheffer RJ, Borlaug BA, Enders FT, Redfield MM: Pulmonary hypertension in heart failure with preserved ejection fraction: a community-based study. J Am Coll Cardiol 2009;53:1119-1126.

28 Leung CC, Moondra V, Catherwood E, Andrus BW: Prevalence and risk factors of pulmonary hypertension in patients with elevated pulmonary venous pressure and preserved ejection fraction. Am J Cardiol 2010;106:284-286.

-29 Bertero T, Lu Y, Annis S, Hale A, Bhat B, Saggar R, Saggar R, Wallace WD, Ross DJ, Vargas SO, Graham BB, Kumar R, Black SM, Fratz S, Fineman JR, West JD, Haley KJ, Waxman AB, Chau BN, Cottrill KA, Chan SY: Systems-level regulation of microRNA networks by miR-130/301 promotes pulmonary hypertension. J Clin Invest 2014;124:3514-3528.

-30 Hirashiki A, Kondo T, Murohara T: The Roles of Classic and Current Prognostic Factors in Pulmonary Hypertension Due to Left Heart Disease. Circ J 2016;80:72-73.

-31 Cameli M, Mandoli GE, Loiacono F, Dini FL, Henein M, Mondillo S: Left atrial strain: a new parameter for assessment of left ventricular filling pressure. Heart Fail Rev 2016;21:65-76.

-32 Rudski LG, Lai WW, Afilalo J, Hua L, Handschumacher MD, Chandrasekaran K, Solomon SD, Louie EK, Schiller NB: Guidelines for the echocardiographic assessment of the right heart in adults: a report from the American Society of Echocardiography endorsed by the European Association of Echocardiography, a registered branch of the European Society of Cardiology, and the Canadian Society of Echocardiography. J Am Soc Echocardiogr 2010;23:685-713; quiz 786-688. 